\title{
Implementasi dan Pengujian Algoritma Fitur Warna pada Image Retrieval
}

\author{
Diny Syarifah Sany \\ Teknik Informatika, Universitas Suryakancana \\ dsy.sany@gmail.com
}

\begin{abstract}
In the era of digitalization, there were so many images produced, so that when doing a retieval image, a good algorithm was needed so that the process was better and more accurate. In image retrieval, there is an image feature extraction algorithm, one of which is by extracting the color features. In this paper, we will test the color feature algorithm that has been spread, how accurate is it by using relevant feedback and using a sample of 1000 images.
\end{abstract}

Keywords: Color Feature Algorithm, Image Retrieval

\begin{abstract}
Abstrak
Pada era digitalisasi gambar dihasilkan sangat banyak sehingga saat melakukan image retieval perlu algortima yang baik agar proses lebih baik dan akurat. Dalam image retrieval ada algoritma ektraksi fitur gambar, salah satunya dengan melakukan ekstraksi pada fitur warna. Pada paper ini akan dilakukan pengujian mengenai algoritma fitur warna yang sudah disebar, seberapa akuratnya dengan menggunakan relevan feedback dan menggunakan sampel 1000 gambar.
\end{abstract}

Kata kunci: Algoritma fitur warna, pengambilan gambar

\section{Pendahuluan}

Ada pepatah yang menyebutkan bahwa gambar lebih memiliki sejuta makna dibandingkan dengan teks, begitupun penglihatan kita, lebih fokus terhadap gambar daripada teks. Di era digital ini, data multimedia yang di seluruh dunia sangatlah banyak. Sehingga peneliti banyak menciptakan algoritma pencarian dan pengambilan data gambar yang diharapkan mampu memberikan kinerja yang baik untuk data multimedia yang sangat besar. Salah satunya dengan menggunakan fitur dari gambar. Tiga fitur visual primitif yaitu warna, tekstur dan bentuk mengacu pada istilah 'konten' dalam pengambilan gambar berbasis konten. Walaupun fitur visual tidak dapat sepenuhnya ditentukan oleh fitur semantik, namun fitur semantik tetap digunakan karena lebih mudah diintegrasikan ke dalam formulasi matematika. Oleh karena itu ekstraksi ciri visual yang baik merupakan salah satu tugas penting untuk merepresentasikan citra secara kompak. Di antara fitur visual, warna adalah fitur yang paling vital, andal, dan banyak digunakan[2].

Database gambar berisi kumpulan data dari berbagai jenis gambar yang memiliki jenis fitur warna harus diekstrak dan disimpan dalam matriks ekstraksi fitur lalu mencocokkan matriks tersebut dengan matriks fitur gambar kueri, jika hasil perhitungannya sesuai dengan gambar database kemudian gambar teratas diambil [3]. Algoritma ini sepenuhnya mempertimbangkan informasi warna global dan lokal, menggabungkan histogram warna fuzzy dan histogram warna blok, mengurangi dimensi fitur warna [1].

Paper ini akan mengimplementasikan algoritma untuk pengambilan gambar dengan menggunakan fitur warna, dan menguji seberapa akuratnya kinerja dari algoritma ini. Algoritma ini diimplementasikan dengan menggunakan python dan Matlab.

\section{Studi Literatur}

Sistem pengambilan gambar dapat didefinisikan sebagai mencari, menelusuri, dan mengambil gambar dari database besar yang terdiri dari gambar digital. Meskipun teknik pengambilan gambar konvensional dan umum menggunakan penambahan metadata yaitu kata kunci teks sehingga dapat melakukan penjelasan kata. Namun pencarian gambar dapat dijelaskan dengan teknik pencarian khusus yang banyak digunakan untuk menemukan gambar. Pengambilan Gambar Berbasis Konten adalah serangkaian teknik untuk mengambil gambar yang relevan secara semantik dari database gambar berdasarkan fitur gambar yang diturunkan secara otomatis [4]. Gambar berwarna adalah kombinasi dari beberapa warna dasar. Dalam MATLAB memecah setiap piksel individu dari gambar berwarna (disebut 'warna sebenarnya') menjadi nilai Merah, Hijau dan Biru. Sebagai hasilnya menjadi 3 matriks, masing-masing mewakili fitur warna[5].

Fitur warna adalah salah satu fitur yang paling banyak digunakan pada fitur level rendah. Dibandingkan dengan fitur bentuk dan tekstur, fitur warna menunjukkan stabilitas yang lebih baik dan lebih tidak sensitif 
terhadap rotasi dan zoom gambar. Warna tidak hanya menambah keindahan objek tetapi juga menambah lebih banyak informasi, yang digunakan sebagai alat yang ampuh dalam pengambilan gambar berbasis konten. Dalam pengindeksan warna, jika diberikan gambar kueri, tujuannya adalah untuk mengambil semua gambar yang komposisi warna dan teksturnya mirip dengan gambar kueri[4].

Berikut ini merupakan bagian dari fitur warna pada gambar,

\section{a. Color Space}

Color space adalah kumpulan dari warna tertentu yang mempresentasikan warna yang dapat direproduksi, baik dalam representasi analog maupun digital. Ekstraksi Color Space yang berbeda menghasilkan metode yang berbeda juga, penggalian dari fitur warna gambar bergantung pada Color Spacenya. Color Space yang umum mengandung HSV, RGB dan YCbCr. Ruang RGB berbasis gambar pengolahan, dan lainnya sebagian besar bisa berubah dari Color Space ini, seperti histogram RGB dan histogram sudut vektor RGB agar dapat beradaptasi dengan karakteristik visual manusia, mengingat hue, saturation dan value maka dikembangkannya ruang warna HSV[1].

$$
\begin{gathered}
V=\max (R, G, B), S=\frac{V-\min (R, G, B)}{V} \\
r^{\prime}=\frac{V-R}{V-\min (R, G, B)} g^{\prime}=\frac{V-G}{V-\min (R, G, B)} b^{\prime}==\frac{V-B}{V-\min (R, G, B)} \\
\text { Then } \\
H^{\prime}=\left\{\begin{aligned}
5+b^{\prime}, R=\max (R, G, B) \text { and } G=\min (R, G, B) \\
1-g^{\prime}, R=\max (R, G, B) \text { and } G \neq \min (R, G, B) \\
1+r^{\prime}, G=\min (R, G, B) \text { and } B=\min (R, G, B) \\
3-b^{\prime}, G=\min (R, G, B) \text { and } B=\min (R, G, B) \\
3+g^{\prime}, B=\min (R, G, B) \text { and } R=\min (R, G, B) \\
5-r^{\prime}, \text { others }
\end{aligned}\right.
\end{gathered}
$$

Gambar 1 Formula konversi cepat dari RGB ke HSV

\section{b. Color Histogram}

Histogram warna merupakan representasi dari distribusi warna pada suatu gambar. Untuk gambar digital, histogram warna mewakili jumlah piksel, yang mencakup ruang warna gambar, sekumpulan semua warna yang mungkin. Fitur color space HSV diekstrak dari citra berdasarkan metode pengambilan untuk membandingkan kesamaan dan mengubah ukuran gambar [1]. Histogram menghitung jumlah piksel dari setiap jenis dan dapat dibuat dengan cepat dengan membaca hanya sekali setiap piksel gambar dan menaikkan bin yang sesuai dari histogram. Histogram warna relatif tidak berubah terhadap titik translate, rotasi di sekitar sumbu pencitraan, rotasi kecil di luar sumbu, perubahan skala, dan oklusi parsial[6].

$$
\mathrm{h}_{\mathrm{c}}=\frac{1}{M \times N} \sum_{0}^{M-1} \sum_{0}^{N-1} \delta\left(f_{i j}-c\right), \forall c \in C
$$

Gambar 2 Rumus Color Histogram

\section{c. Color Moment}

Informasi warna didistribusikan pada momen warna rendah, terutama untuk orde pertama, kedua dan ketiga. Jadi, Mean, Varians dan skewness cukup mewakili distribusi fitur warna pada sebuah gambar [1]. Mengingat ruang warna $\mathrm{RGB}$, informasi statistik sederhana dari warna dapat diturunkan sebagai:

$$
\begin{aligned}
& \mu_{i}=\frac{1}{n} \sum_{j=1}^{n} h_{i j} \\
& \sigma_{i}=\left(\frac{1}{n} \sum_{j=1}^{n}\left(h_{i j-} \mu_{i}\right)^{2}\right)^{\frac{1}{2}} \\
& s_{i}=\left(\frac{1}{n} \sum_{j=1}^{n}\left(h_{i j}-\mu_{i}\right)^{3}\right)^{\frac{1}{3}} \\
& \text { Gambar } 3 \text { Penurunan Color Moment }
\end{aligned}
$$

\section{Implementasi}

Secara keseluruhan sistem color feature extraction pada paper ini terdiri beberapa tahap, yaitu:

a. Get file dalam database

Data yang digunakan adalah database COREL1000, dengan 10 kelas gambar dan masing-masing terdapar 100 gambar.

b. File extraction

Flow file extraction dapat dilihat pada gambar berikut,

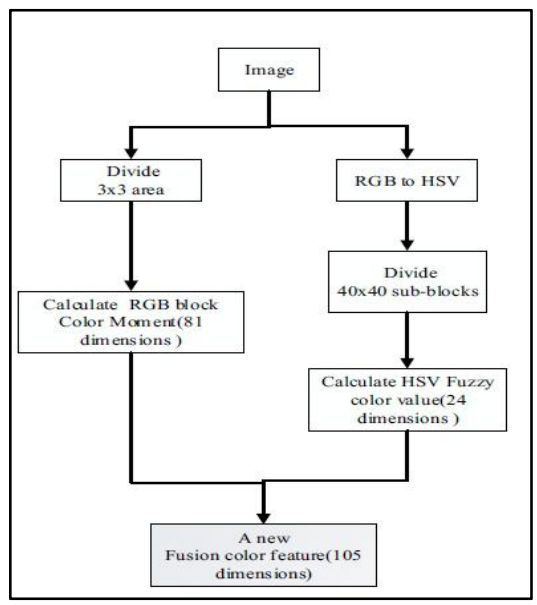

Gambar 4 Flow File Extraction

Gambar diproses ke dalam Fuzzy dan Blok Color Momenr, sehingga akhirnya menghasilkan 105 fitur yakni 81 dari color moment dan 24 dari fuzzy.

c. Evaluasi

Teknik evaluasi yang dilakukan adalah dengan menghitung Recall, Precission, dan F-Measurement.

d. Relevan Feedback

Teknik relevan feedback yang dilakukan adalah dengan menggunakan Multipoint query.

Terdapat 2 metode yang digunakan dalam color extraction ini, yaitu

a. Fuzzy

Proses dalam fuzzy ini terdiri dari

- Pembagian setiap image kedalam sub block image $40 \times 40$

- Perhitungan Konversi RGB ke HSV

- Fungsi aktifasi sesuai rule yang di propose Fungsi ini merupakan fungsi pengelompokan, untuk 10 bins, dikelompokkan menjadi 8 kelompok untuk nilai $\mathrm{H}, 2$ kelompok untuk nilai $\mathrm{S}$ dan 3 kelompok untuk V. Dan untuk 24 bins, hanya mengelompokkan $\mathrm{S}$ dan $\mathrm{V}$, keduanya dikelompokkan menjadi 3 bagian.

- Judging Rule

Terdapat dua fungsi judge, 10 dan 24 bins. Dari 10 dan 24 tersebut, menghasilkan sebuah fitur nilai tertentu. Ouput secara umum menghasilkan 7 
warna, tetapi memiliki degradasi warna yang berbeda, yaitu deep, light, dan medium.

- Setelah mendapatkan nilai-nilai tersebut, dihitung nilai frekuensi yang masuk kedalam kelompokkelompok tersebut, dan nilai frekuensi itulah yang dijadikan sebagai fitur dari fuzzy histogram.

- Nilai Fuzzy histogram = ( 7 warna dasar X 3 fariasi warna $)+3$ warna dasar $=24$ fitur.

\section{b. Color Moment}

Setiap gambar dalam database di bagi menjadi $3 \times 3$ region, dan setiap region dilakukan perhitungan block moment, yaitu mean, standard deviasi dan skewness. Adapun rumus dari ketiganya :

Mean

$$
E_{i}=\sum_{j=1}^{N} \frac{1}{N} p_{i j}
$$

Standard deviasi

$$
\begin{aligned}
& \sigma_{i}=\sqrt{\left(\frac{1}{N} \sum_{j=1}^{N}\left(p_{i j}-E_{i}\right)^{2}\right)} \\
& \text { Skewness } \\
& s_{i}=\sqrt[3]{\left(\frac{1}{N} \sum_{j=1}^{N}\left(p_{i j}-E_{i}\right)^{3}\right)}
\end{aligned}
$$

Sehingga total sub block image $\mathrm{X}$ moment $\mathrm{X}$ RGB $=$ $(3 * 3) *(3) *(3)=81$ fitur.

Total fitur dari fuzzy dan hitogram :

Fuzzy(24) + histogram(81) + no_image(1) + no_class $(1)=107$ fitur

\section{c. Teknik Relevance Feedback}

Teknik Relevan Feedback yang digunakan adalah Multipoint query. Pencarian nilai awal dilakukan dengan single point. Dan untuk relevance feedback kami menggunakan Multipoint query. Setelah melakukan pencarian lalu menampilkan query berdasarkan ranking dengan batas 20 image dengan kemiripan yang paling tinggi. Dengan batasan setiap fitur dibandingkan dengan fitur lainnya untuk setiap bagiannya 20 (dijelaskan lebih detail pada bagian experimen).

Perhitungan relevance feedback :

$Q 2=(Q 1+R F(n)) /(n+1)$

Dimana Q2 adalah nilai query baru yang dihasilkan dari nilai query awal, ditambahkan dengan semua nilai image yang dianggap relevance(RF) dengan jumlahnya adalah $n$, dibagi dengan $n+1(+1$ untuk nilai query awal). Kami menggunakan model ini, dikarenakan menurut kami model ini cukup baik untuk menemukan image tersembunyi(mirip dengan LDA pada topik dokumen) dan cukup baik apabila memiliki nilai rata-rata yang cukup tinggi.

\section{d. Teknik Evaluasi}

Teknik Evaluasi yang digunakan adalah Precision, Recall dan F Measure.

- Nilai Precision diambil dari dari data yang benar diantara data yang ditampilkan(TP) dibagi dengan jumlah semua data yang terambil (TP+FP).

Precision $=\mathrm{TP} /(\mathrm{TP}+\mathrm{FP})$

- Nilai Recall diambil dari data yang seharusnya benar. Karena seharusnya apabila data benar terambil pada suatu class maksimal adalah 100, maka kami menggunakan nilai 100 sebagai nilai keseharusan sebuah image bila terambil benar. Misalnya Image Dinosaurus benar, maka minimal ada 100 image jenis dinosaurus berada di peringkat 100 dari 1000 image. Image-image yang berada di 100 peringkat ini tidak ditampilkan, tetapi diproses bersama ketika proses pencarian. Sehingga image yang benar yang berada pada 100 image rangking pertama similarity(TP), dibagi dengan 100 image jumlah image yang seharusnya terambil dan itu benar $(\mathrm{TP}+\mathrm{FN})$.

Recall $=\mathrm{TP} /(\mathrm{TP}+\mathrm{FN})$

- F Measure diambil dari perhitungan recall dan precision.

$\mathrm{F} 1=2 \mathrm{xRecall} \times$ Precision $/($ Recall + Precision $)$

\section{Pengujian}

Eksperimen dilakukan dengan:

a. Percobaan pertama dengan nilai treshold sebagai variabel perubah.



Gambar 5 Hasil Percobaan dengan nilai treshold 0

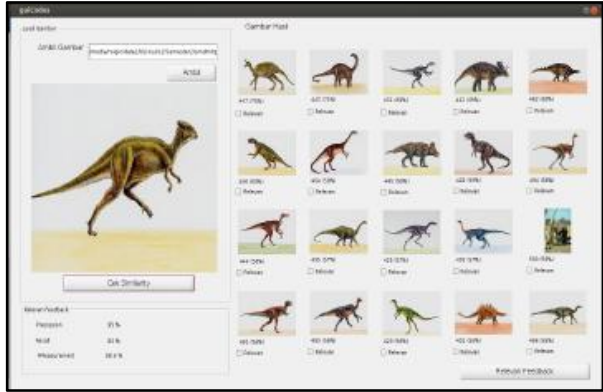

Gambar 6 Hasil Percobaan dengan nilai treshold 5

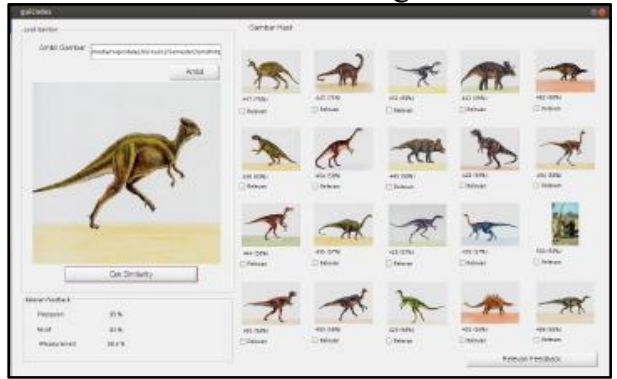

Gambar 7 Hasil Percobaan dengan nilai treshold 10

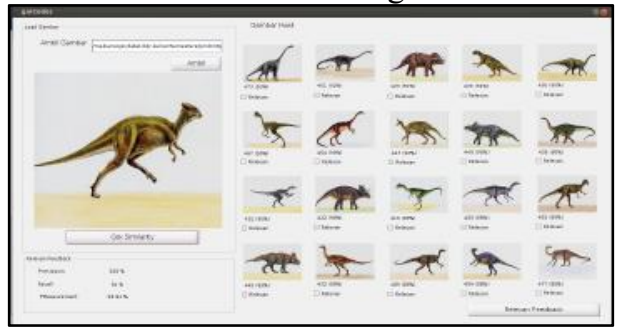

Gambar 8 Hasil Percobaan dengan nilai treshold 20 


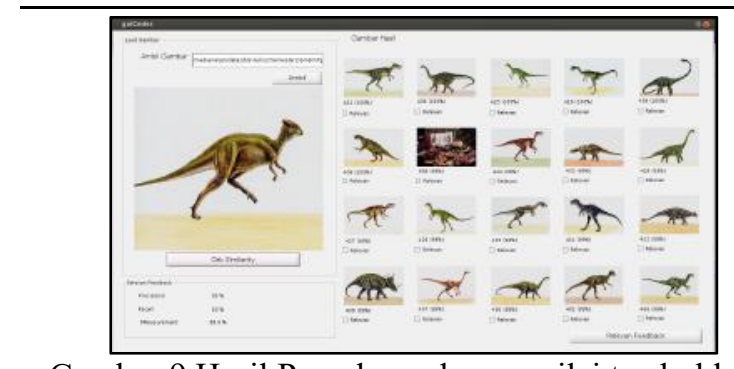

Gambar 9 Hasil Percobaan dengan nilai treshold 100

b. Percobaan kedua dengan melakukan perhitungan nilai setiap class dan relevance feedbacknya

Setiap class diuji coba apakah dengan menggunakan aplikasi yang telah dibangun, hasilnya:

Pengujian gambar dilakukan dengan mengambil satu gambar pada tiap kelas secara random, gambar yang diuji:

Tabel 1 Gambar yang diuji tiap kelas

\begin{tabular}{|c|c|}
\hline Nama Kelas & Gambar No \\
\hline African & 7 \\
\hline Beach & 163 \\
\hline Building & 215 \\
\hline Bus & 311 \\
\hline Dinosaurus & 469 \\
\hline Elephant & 554 \\
\hline Flower & 656 \\
\hline Horse & 788 \\
\hline Mountain & 875 \\
\hline Food & 906 \\
\hline
\end{tabular}

Tabel 2 Tabel pengukuran setiap kelas sebelum melakukan relevan feedback

\begin{tabular}{|l|c|c|c|}
\hline Nama Kelas & $\begin{array}{c}\text { Precissi } \\
\text { on }\end{array}$ & Recall & $\begin{array}{c}\text { F- } \\
\text { Measurement }\end{array}$ \\
\hline African & 0.5 & 0.22 & 0.3056 \\
\hline Beach & 0.5 & 0.26 & 0.3421 \\
\hline Building & 0.35 & 0.16 & 0.2196 \\
\hline Bus & 0.75 & 0.51 & 0.6071 \\
\hline Dinosaurus & 1 & 0.93 & 0.9637 \\
\hline Elephant & 0.55 & 0.27 & 0.3622 \\
\hline Flower & 1 & 0.61 & 0.7578 \\
\hline Horse & 1 & 0.52 & 0.6842 \\
\hline Mountain & 0.45 & 0.25 & 0.3214 \\
\hline Food & 0.30 & 0.29 & 0.2949 \\
\hline
\end{tabular}

Tabel 3 Tabel pengukuran setiap kelas sebelum melakukan relevan feedback satu kali:

\begin{tabular}{|l|c|c|c|}
\hline $\begin{array}{c}\text { Nama } \\
\text { Kelas }\end{array}$ & Precission & Recall & $\begin{array}{c}\text { F- } \\
\text { Measurement }\end{array}$ \\
\hline African & 0.65 & 0.39 & 0.4875 \\
\hline Beach & 0.65 & 0.37 & 0.4716 \\
\hline
\end{tabular}

\begin{tabular}{|l|c|c|c|}
\hline Building & 0.45 & 0.34 & 0.3873 \\
\hline Bus & 0.85 & 0.45 & 0.5885 \\
\hline Dinosaurus & $\begin{array}{c}\text { Tidak } \\
\text { dilakukan }\end{array}$ & $\begin{array}{c}\text { Tidak } \\
\text { dilakukan }\end{array}$ & $\begin{array}{c}\text { Tidak } \\
\text { dilakukan }\end{array}$ \\
\hline Elephant & 0.75 & 0.39 & 0.5132 \\
\hline Flower & $\begin{array}{c}\text { Tidak } \\
\text { dilakukan }\end{array}$ & $\begin{array}{c}\text { Tidak } \\
\text { dilakukan }\end{array}$ & $\begin{array}{c}\text { Tidak } \\
\text { dilakukan }\end{array}$ \\
\hline Horse & $\begin{array}{c}\text { Tidak } \\
\text { dilakukan }\end{array}$ & $\begin{array}{c}\text { Tidak } \\
\text { dilakukan }\end{array}$ & $\begin{array}{c}\text { Tidak } \\
\text { dilakukan }\end{array}$ \\
\hline Mountain & 0.45 & 0.30 & 0.36 \\
\hline Food & 0.35 & 0.25 & 0.2917 \\
\hline
\end{tabular}

\section{Simpulan}

Dari percobaan relevance feedback dapat disimpulkan bahwa, jika ada class image tersebut cukup dominan, maka apabila dilakukan relevance feedback maka bisa menghasilkan nilai yang lebih baik. Tetapi bisa sebaliknya, apabila nilai rata-rata pada class tersebut cukup buruk, maka bisa jadi tidak akan pernah menemukan similarity yang lebih baik dan menurunkan nilai precision dan recall pada pencarian relevance feedback selanjutnya.

\section{Daftar Pustaka}

[1] Mengzhe Li, Xiuhua Jiang, An Improved Algorithm Based on Color Feature Extraction for Image Retrieval, 2016 8th International Conference on Intelligent Human-Machine Systems and Cybernetics

[2] S Divya, W Rajesh, and G Manasi. A Review: Color Feature Extraction Methods for Content Based Image Retrieval, IJCEM International Journal of Computational Engineering \& Management, Vol. 18 Issue 3, May 2015.

[3] S. Dhanashree Kalel , M. Pooja,and B Ramdas Bagawade, Color, Shape and Texture feature extraction for Content Based Image Retrieval System: A Study, International Journal of Advanced Research in Computer and Communication Engineering Vol. 5, Issue 4, April 2016

[4] Sanjay Kumar, Feature Extraction Techniques Based on Color Images, Special Conference Issue: National Conference on Cloud Computing \& Big Data.

[5] R.Venkata , D.Rajya and K.V.N Sunitha, Feature Extraction Methods For Color Image Similarity, Advanced Computing: An International Journal ( ACIJ ), Vol.3, No.2, March 2012 